\title{
Prevalence, risk factors and burden of diabetic retinopathy in China: a systematic review and meta-analysis
}

\author{
Peige Song ${ }^{1}$, Jinyue $Y u^{2}$, \\ Kit Yee Chan', Evropi \\ Theodoratou ${ }^{1}$, Igor Rudan ${ }^{1}$ \\ ${ }^{1}$ Centre for Global Health Research, \\ Usher Institute of Population Health \\ Sciences and Informatics, University \\ of Edinburgh, Edinburgh, Scotland, \\ United Kingdom \\ ${ }^{2}$ UCL Great Ormond Street Institute \\ of Child Health, University College \\ London, London, United Kingdom
}

Background Diabetic retinopathy (DR), the primary retinal vascular complication of diabetes mellitus (DM), is a leading cause of vision impairment and blindness in working-age population globally. Despite mounting concerns about the emergence of DM as a major public health problem in the largest developing country, China, much remains to be understood about the epidemiology of DR. We aimed to investigate the prevalence of and risk factors for DR, and estimate the burden of DR in China in 2010.

Methods China National Knowledge Infrastructure (CNKI), Wanfang, Chinese Biomedicine Literature Database (CBM-SinoMed), PubMed, Embase and Medline were searched for studies that reported the prevalence of and risk factors for DR in Chinese population between 1990 and 2017. A random-effects meta-analysis model was adopted to pool the overall prevalence of DR. Variations in the prevalence of DR in different age groups, DM duration groups and settings were assessed by subgroup meta-analysis and meta-regression. Odds ratios (ORs) of major risk factors were pooled using random-effects meta-analysis. The number of people with DR in 2010 was estimated by multiplying the age-specific prevalence of DR in people with DM with the corresponding number of people with DM in China. Finally, the national number of people with DR was distributed into six geographic regions using a risk factor-based model.

Results A total of 31 studies provided information on the prevalence of DR and 21 explored potential risk factors for DR. The pooled prevalence of any DR, nonproliferative DR (NPDR) and proliferative DR (PDR) was 1.14\% (95\% $\mathrm{CI}=0.80-1.52), 0.90 \%(95 \% \mathrm{CI}=0.56-1.31)$ and $0.07 \%(95 \% \mathrm{CI}=0.02-0.14)$ in general population; In people with $\mathrm{DM}$, the pooled prevalence rates were $18.45 \%(95 \% \mathrm{CI}=14.77-22.43), 15.06 \%(95 \% \mathrm{CI}=11.59-18.88)$ and $0.99 \%$ (95\% CI =0.40-1.80) for any DR, NPDR and PDR, respectively. The prevalence of any DR in DM patients peaked between 60 and 69 years of age, and increased steeply with the duration of DM. DM patients residing in rural China were at a higher risk to have DR than those in urban areas. In addition, insulin treatment, elevated FBG level and higher HbAlc concentration were confirmed to be associated with a higher prevalence of DR in people with DM, with meta-ORs of 1.99 (95\% CI $=1.34-2.95), 1.33$ (95\% CI=1.12-1.59) and 1.15 (95\% CI=1.091.20) respectively. In 2010, a total of 13.16 million ( $95 \% \mathrm{CI}=8.95-18.00)$ Chinese aged 45 years and above were living with DR, among whom the most were in South Central China and the least were in Northwest China.

Conclusions DR has become a serious public health problem in China. Optimal screening of and interventions on DR should be implemented. Improved epidemiological studies on DR are still required.

\section{Correspondence to:}

\section{Peige Song}

Centre for Global Health Research Usher Institute of Population Health Sciences and Informatics

University of Edinburgh

Edinburgh EH8 9AG

United Kingdom

p.song@sms.ed.ac.uk 
Diabetic retinopathy (DR), the primary retinal vascular complication of diabetes mellitus (DM), is a leading cause of vision impairment and blindness in the working-age population [1-4]. In the early course of the disease, DR is generally asymptomatic. If left untreated, DR can seriously impair vision, and eventually progress to blindness [1,3]. Apart from its devastating visual effects that might lead to reduced mobility, depression and lower quality of life, DR is also associated with a higher risk of systemic vascular complications, imposing a noteworthy burden on individuals, households, communities and societies [5-7]. DR is a progressive disease that can be broadly divided into two stages according to its severity: nonproliferative and proliferative. Nonproliferative DR (NPDR) is characterized by microaneurysms, cotton-wool spots, intraretinal microvascular abnormalities, hard exudates and venous beading, whereas proliferative DR (PDR) is hallmarked by neovascularization of the optic disc or elsewhere, pre-retinal and vitreous haemorrhage [1,8]. Taken individually, PDR is less common but more sight-threatening than NPDR [1-3,8,9].

Although available diagnostic and therapeutic advancements, such as optimum management of DM and early detection of DR, can substantially reduce the risk of visual deterioration, DR remains an important cause of visual impairment and blindness globally [10-16]. In 2010, 3.7 million people were visually impaired and 0.8 million were blind because of DR, accounting for $1.9 \%$ of all visually impaired cases and $2.6 \%$ of all blind cases worldwide [13]. With DM having reached epidemic proportions worldwide, estimating the prevalence of DR in both the general population and those with DM is imperative for driving better health policy making and improved programming $[13,15]$. By pooling data from 35 population-based studies across the world, the Global DR Study estimated that the prevalence of any DR, PDR and vision-threatening DR (severe retinopathy and macular oedema) were $34.6 \%, 7.0 \%$ and $10.2 \%$ respectively among individuals with DM, translating to approximately 93 million people with any DR, 17 million with PDR and 28 million with vision-threatening DR worldwide in 2010 [2]. Unless substantial improvements occur in the prevention and treatment of DR, the prevalence and burden of DR will continue to escalate as the global population ages and the epidemic of DM expands [17-19]. In addition, evaluation of risk factors for DR is of special importance in optimal clinical management. Similar to other common complications of DM, DR is a sentinel indicator of the progression of DM, thus its prevalence, not surprisingly, associated with the duration and severity of DM $[2,4,20]$. In the Global DR Study, longer DM duration has been recognised as a key risk factor for DR in people with $\mathrm{DM}$, as well as higher levels of haemoglobin $\mathrm{Alc}(\mathrm{HbAlc})$ and blood pressure. Moreover, individuals with type 1 DM (T1DM) are more likely to develop DR than those with type 2 DM (T2DM) [2,4].

Despite mounting concerns about the emergence of DM as a major public health problem in the largest developing country, China, epidemiological data on DR in Chinese population are still rather scarce or inconsistent $[9,21-23]$. Thus far, there is still no national population-based data on the prevalence and burden of DR in China, and the existing surveys on DR are restricted to local characteristics, study methodologies, ascertainment and classification of DR, limiting direct comparisons between individual studies [22]. A systematic review and meta-analysis by Liu and colleagues, dating back to 2012, has provided the first overview of the DR prevalence in China. Based on 19 individual studies, their meta-analysis suggested that the pooled prevalence rates of any DR, NPDR and PDR in general Chinese population were $1.3 \%, 1.1 \%$, and $0.1 \%$ and those in people with DM were $23.0 \%, 19.1 \%$, and $2.8 \%$ respectively [22]. Thereafter, a growing body of epidemiological data on DR has become available in China, yet virtually none of them has been systematically appraised, underscoring the need for an updated analysis [24,25]. Moreover, the effects of major risk factors for DR are still discrepant and inconclusive among the Chinese population, which need to be systematically evaluated in an evidence-based fashion.

To fill the gaps outlined above, we conducted a comprehensive systematic review, in both Chinese and English databases, to retrieve studies that reported the epidemiology of DR in China from 1990 onwards. Based on the existing evidence, we aimed to: (1) pool the overall prevalence of DR in both general Chinese population and people with DM; (2) estimate the effects of demographic and geographic variables on the prevalence of DR in people with DM; (3) assess the major risk factors for DR in people with DM; and (4) quantify the national and subnational burden of DR in 2010.

\section{METHODS}

\section{Systematic review}

This systematic review and meta-analysis adheres to the Preferred Reporting Items for Systematic Reviews and Meta-Analyses (PRISMA) guidelines and the Guidelines for Accurate and Transparent Health Estimates Reporting (GATHER) statement [26,27]. 


\section{Search strategy}

Three Chinese and three English electronic bibliographic databases, namely China National Knowledge Infrastructure (CNKI), Wanfang, Chinese Biomedicine Literature Database (CBM-SinoMed), PubMed, Embase, and Medline, were searched to locate all relevant publications that reported the epidemiology of DR in China. Our comprehensive search strategies combined terms of diabetic retinopathy, epidemiology (incidence, prevalence, morbidity, mortality, epidemiology) and China (China, Chinese, Hong Kong, Macau, Taiwan) using both controlled vocabularies (eg, Medical Subject Heading terms) and free text words. Search queries were optimised to fit the specific features of each database, and the full search strategies are detailed in Table S1 in Online Supplementary Document. To supplement the electronic database search, reference lists of eligible publications and related reviews were also scanned to identify other potentially pertinent studies. The literature search was limited to studies published between January 1990 and December 2017. No language restrictions were imposed on searches or search results.

\section{Inclusion and exclusion criteria}

To be included in the systematic review and meta-analysis, studies had to be population-based and reported the prevalence of DR or risk factors for DR. Depending on how the study population was sought, the identified population-based studies can be classified into three categories: community-based, primary health care management (PHCM)-based and registry-based. Community-based studies derived their study sample from the general population (eg, cluster sampling of households), whereas PHCM-based and registry-based studies derived their study sample from all the primary care settings or primary care systems in a defined geographical area. Thus, both PHCM-based and registry-based studies attempted to capture all, or at least a random sample, of people with DM in a defined geographical area. For the purpose of pooling prevalence rates of DR, the included studies must be community-based, and of particular note, include both newly detected and physician-diagnosed DM cases simultaneously (to avoid overestimation); To assess the risk factors for DR in people with DM, the included studies could be community-based, PHCM-based or registry-based, where DM cases could be either newly detected or physician-diagnosed, or both. To avoid suspected bias inherent to univariate analysis, the estimation of odds ratios (ORs) in studies that reported the risk factors for DR must be based on a multivariate study design.

Studies that were conducted in the T1DM group were excluded, whereas those focused on people with T2DM were retained. Studies that contained both T1DM and T2DM cases were not excluded if the proportion of people with T1DM was small $(<10 \%)$. For studies where the type of DM was not specified but all other criteria were fulfilled, it was assumed that those studies contained both T2DM cases and a small proportion of T1DM cases. Otherwise, the type of DM could be speculated by the age at diagnosis of DM (if available), where people diagnosed before 30 years were deemed as with T1DM and those after 30 years were T2DM $[2,28]$. To be eligible for inclusion, studies must have undertaken fundus photography (FP) to ascertain DR and provided numerical estimates of DR prevalence. Reviews, commentaries and studies where the prevalence rates were calculated based on the number of eyes with DR rather than the number of affected individuals were excluded.

\section{Study selection and data extraction}

After deleting duplicate records within and between different bibliographic databases, the remaining titles and abstracts were independently reviewed by two authors (PS and JY) to identify potentially eligible articles that required a full appraisal. In cases of multiple publications from the same study or overlapping data, preference was given to the most recent one or the one with the most inclusive information. Consensus was achieved for any discrepancies in study eligibility through discussion. With a predefined data-collection form, the following information was extracted from the included studies, where possible:

1) Characteristics of the study: author(s), publication year, study year, study type (community-based, PHCM-based or registry-based), sampling method, study design (cross-sectional or cohort), study setting (urban, rural or mixed) and location, geographic region, DR assessment method and grading system;

2) Characteristics of the sample (general population and people with DM): number of the sample, age (age range, mean or median age), gender (male, female or mixed), DM definition, DM classification (T1DM or T2DM, newly detected or physician-diagnosed), and duration of DM;

3) Prevalence data: the number of people with DR and the number of participants who had been tested for DR, by age, DM duration, gender, setting and DR subtype;

4) Risk factor data: definition of risk factor, OR and corresponding confidence intervals (CIs). 
According to the definitions from National Bureau of Statistics of China, the geographic regions where the studies were carried out were classified into six categories: East China, North China, Northeast China, Northwest China, South Central China, and Southwest China (see Table 1) [29,30]. Missing values for the median year of study were imputed by subtracting three years (the average time-lag from investigation to publication in studies with available data) from their publication years, and this was done for six individual studies. In this study, we further classified DR as NPDR and PDR. Therefore, relevant data were extracted from the included studies for different subtypes of DR respectively, wherever available.

Table 1. The six geographic regions in China

\begin{tabular}{ll} 
REEION & InGLUDED PRovincES \\
North China & Beijing Municipality, Hebei province, Inner Mongolia Autonomous Region, Shanxi province, Tianjin Municipality \\
\hline Northeast China & Heilongjiang province, Jilin province, Liaoning province \\
\hline East China & Anhui province, Fujian province, Jiangsu province, Jiangxi province, Shandong province, Shanghai Municipality, Zhejiang province \\
\hline South Central China & Guangdong province, Guangxi Zhuang Autonomous Region, Hainan province, Henan province, Hubei province, Hunan province \\
\hline Southwest China & Chongqing Municipality, Guizhou province, Sichuan province, Tibet Autonomous Region, Yunnan province \\
\hline Northwest China & Gansu province, Ningxia Hui Autonomous Region, Qinghai province, Shaanxi province, Xinjiang Uyghur Autonomous Region
\end{tabular}

\section{Statistical analysis}

\section{Pooling prevalence of DR in China}

The crude prevalence of DR was first computed for each study and then double-arcsine transformed by using the Freeman-Tukey method [31-33]. Heterogeneity among eligible studies was assessed with the Cochran's Q statistic and $I^{2}$ index (the proportion of total variability due to true between-study heterogeneity beyond chance) [34,35]. A p-value of less than 0.1 showed the presence of heterogeneity, and $I^{2}$ values of less than 25\% corresponded to mild heterogeneity, of from $25 \%$ to $50 \%$ reflected moderate heterogeneity, and of greater than 50\% represented high heterogeneity, respectively [34-36]. Because of the substantial heterogeneity noted between individual studies, a random-effects (DerSimonian and Laird method) meta-analysis was used to adjust for variability and pool the study-specific prevalence rates $[32,36]$. For each meta-analysis, a leave-one-out sensitivity analysis was developed to assess the robustness of the pooled results. By removing one study at a time to run the meta-analysis without it, the sensitivity analysis could test whether single studies had a disproportionally excessive influence on the pooled results [37]. Publication bias was checked by visual inspection of funnel plots, and tested for significance with Egger's regression test for funnel plot asymmetry and Begg's rank correlation test [38-40]. The prevalence rates of any DR, NPDR and PDR in both general population and people with DM were pooled with this approach respectively.

\section{Subgroup meta-analysis and meta-regression of DR prevalence in people with DM}

For the prevalence of any DR in people with DM, potential sources of heterogeneity were investigated using subgroup meta-analysis and meta-regression. In subgroup meta-analysis, the prevalence of any DR was estimated for different age groups and DM duration groups. This was done because age- and DM duration-specific prevalence of any DR in people with DM was universally provided by the included studies. Moreover, the individual associations between prevalence of any DR and study-level variables were evaluated by univariable meta-regression using unrestricted maximum likelihood method. The prespecified variables included gender (male vs female), setting (urban, rural and mixed), geographic region and study year. Because only a few variables were individually significant, a multivariable meta-regression was not subsequently performed.

\section{Meta-analysis of risk factors for DR in people with DM}

To investigate the risk factors for any DR in people with DM, a random-effects meta-analysis was employed a priori because of anticipated variation in study populations, geography and study design. As a rule, we only included risk factors that were investigated in at least three studies using multivariate design, and the definitions of the same risk factor should be similar across all included studies. Finally, 11 factors (advanced age, male gender, DM duration, insulin treatment, fasting blood glucose [FBG], 2-hour postprandial blood glucose [2h-PBG], glycated haemoglobin Alc [HbAlc], total cholesterol [TC], tri- 
glyceride $[\mathrm{TG}]$, body mass index [BMI], systolic blood pressure [SBP]) met our criteria and were included in meta-analysis.

\section{Estimation of national and subnational burden of DR in 2010}

At the final stage, the national number of cases with any DR ("any DR envelope") was estimated by multiplying the age-specific prevalence of any DR in people with DM with the corresponding number of people with DM in China. For this purpose, the 2011 national baseline survey of China Health and Retirement Longitudinal Study (CHARLS), a nationally representative survey of Chinese people aged 45 years and older by using a four-stage, stratified, cluster sampling procedure, was selected to provide prevalence estimates of DM in China for the year 2010, and the Chinese population data were obtained from the United Nations Population Division (UNPD) [41]. The number of people with DM was estimated with the prevalence of DM and the corresponding population size. The study design and implement of CHARLS have been published previously and the procedures for deriving the prevalence of DM are outlined in Table S2 and Figures S1-S2 in Online Supplementary Document [42,43]. Then the national number of people with any DR ("any DR envelope") was distributed into six geographical regions in China (East China, North China, Northeast China, Northwest China, South Central China, Southwest China) by taking the effects of major risk factors on the prevalence of any DR in those regions $[44,45]$. Four statistically significant risk factors (advanced age, rural setting, elevated FBG level and higher HbAlc concentration) were chosen because they were all objective indicators. DM duration and insulin treatment, although being significantly associated with the prevalence of any DR, were not selected because they were highly subject to the diagnosis and treatment of DM, socioeconomic circumstances or geography, and therefore might introduce bias in our estimation of DR burden at the subnational level.

A two-sided p-value of less than 0.05 indicated statistical significance except for the $\mathrm{Q}$ statistics, in which a significance level of less than 0.1 was specified. All statistical analyses were done with $\mathrm{R}$ version 3.3.0 (R Foundation for Statistical Computing, Vienna, Austria) and STATA version 14.0 (STATA Corporation, College Station, TX, USA). All maps were drawn by ArcMap version 10.1 (Environmental Systems Re-

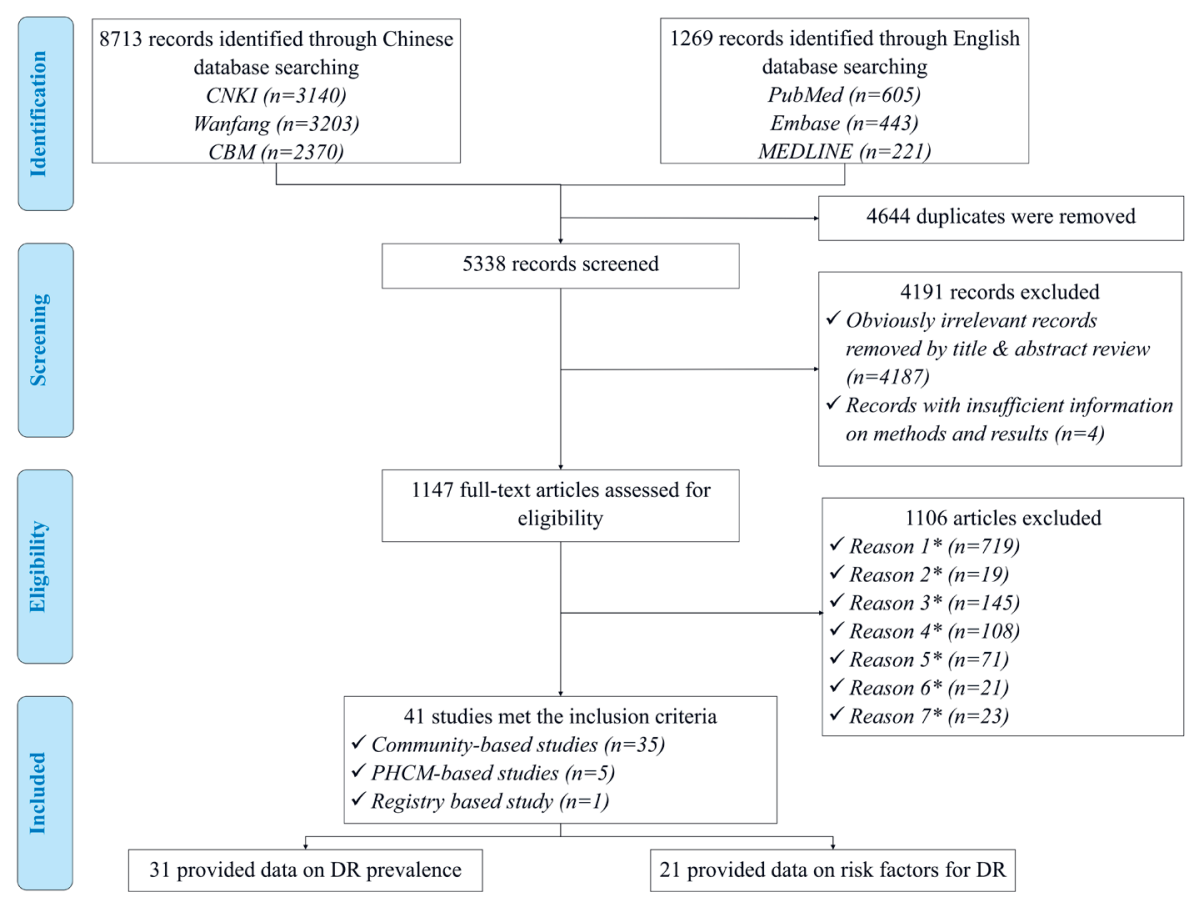

Figure 1. Systematic review flow diagram of studies on the prevalence of and risk factors for diabetic retinopathy (DR) in China. PHCM - Primary Health Care Management; *Reason 1 - Studies that were not community-based, PHCM-based or registry-based; *Reason 2 - Studies that were not based in China; * Reason 3 - Articles with no numerical prevalence measure of DR or didn't report risk factor for DR in people with diabetes mellitus (DM); * Reason 4 Studies with no clear assessment methods or grading systems of DR; *Reason 5 - Studies that were specifically conducted in people with unrepresentative characteristics (hypertensive patients, people with reduced vision, etc.); *Reason 6 - Multiple publications of the same study; * Reason 7 - Studies that didn't include both newly detected and diagnosed DM cases. search Institute, Redlands, CA, USA) using the China base map obtained from the Global Administrative Areas (GADM) database (GADM, 2015, version 2.0; www. gadm.org).

\section{RESULTS}

\section{Summary of systematic review}

The initial search strategy yielded 9982 records. After removal of 4644 duplicates, a total of 5338 records were reviewed for relevance by titles and abstracts, of which 1147 were assessed in full-text form. Finally, 41 articles met eligibility criteria and were included in the systematic review. Of these, 31 studies provided information on the prevalence of DR and $21 \mathrm{ex}$ plored potential risk factors for DR. The process of study selection is summarised in Figure $\mathbf{l}$ according to the PRISMA guidelines. A full list of the included studies is shown in Table S3 in Online Supplementary Document. 
Table 2. Main characteristics of the included studies on the prevalence of and risk factors for diabetic retinopathy in China*

\begin{tabular}{|c|c|c|}
\hline \multirow[b]{2}{*}{ Сharacteristics of study } & \multicolumn{2}{|c|}{ Number Of Studies (\%) } \\
\hline & $\begin{array}{l}\text { Studies on DR prevalence } \\
\qquad(\mathrm{n}=31)\end{array}$ & $\begin{array}{c}\text { Studies on risk } \\
\text { factors for DR }(n=21)\end{array}$ \\
\hline \multicolumn{3}{|l|}{ Year published: } \\
\hline 1990-1999 & $4(12.9)$ & $1(4.8)$ \\
\hline $2000-2009$ & $7(22.6)$ & $5(23.8)$ \\
\hline 2010-2017 & $20(64.5)$ & $15(71.4)$ \\
\hline \multicolumn{3}{|l|}{ Study design: } \\
\hline Community-based & $31(100.0)$ & $15(71.4)$ \\
\hline PHCM-based & $0(0.0)$ & $5(23.8)$ \\
\hline Registry-based & $0(0.0)$ & $1(4.8)$ \\
\hline \multicolumn{3}{|l|}{ Setting: } \\
\hline Urban & $12(38.7)$ & $15(71.4)$ \\
\hline Rural & $7(22.6)$ & $3(14.3)$ \\
\hline Mixed & $12(38.7)$ & $3(14.3)$ \\
\hline \multicolumn{3}{|l|}{ Gender: } \\
\hline Mixed & $13(41.9)$ & $3(14.3)$ \\
\hline Both & $18(58.1)$ & $18(85.7)$ \\
\hline \multicolumn{3}{|l|}{ Sample size of DM: } \\
\hline$\leq 200$ & $6(19.4)$ & $2(9.5)$ \\
\hline $201-500$ & $12(38.7)$ & $5(23.8)$ \\
\hline $501-1000$ & $9(29.0)$ & $6(28.6)$ \\
\hline$>1000$ & $4(12.9)$ & $8(38.1)$ \\
\hline \multicolumn{3}{|l|}{ Grading system: } \\
\hline ICDRDSS & $12(38.7)$ & $11(52.4)$ \\
\hline ETDRS & $6(19.4)$ & $7(33.3)$ \\
\hline NOFDG & $3(9.7)$ & $1(4.8)$ \\
\hline NCOFD & $9(29.0)$ & $2(9.5)$ \\
\hline CBM & $1(3.2)$ & $0(0.0)$ \\
\hline \multicolumn{3}{|l|}{ Geographic regions: } \\
\hline North China & $11(35.5)$ & $7(33.3)$ \\
\hline Northeast China & $5(16.1)$ & $3(14.3)$ \\
\hline East China & $5(16.1)$ & $8(38.1)$ \\
\hline South Central China & $4(12.9)$ & $2(9.5)$ \\
\hline Southwest China & $1(3.2)$ & $1(4.8)$ \\
\hline Northwest China & $5(16.1)$ & $0(0.0)$ \\
\hline
\end{tabular}

DR - diabetic retinopathy, DM - diabetes mellitus, PHCM - Primary Health Care Management, ICDRDSS - International Clinical Diabetic Retinopathy Disease Severity Scale, ETDRS - Early Treatment of Diabetic Retinopathy Study, NOFDG - National Ocular Fundus Diseases Group, NCOFD - National Conference on Ocular Fundus Diseases, CBM - China Medical Board

*11 studies reported both prevalence of DR and risk factors for DR, therefore the sum of the number of studies exceeded 41.
All included studies were cross-sectional in design and assessed DR by using FP. Table 2 summarises the main characteristics of all included studies, and Table S4 in Online Supplementary Document lists the detailed characteristics of every study. For the 31 studies that reported the prevalence of DR and the 21 studies on risk factors for DR, the majority were published after 2010, implying the necessity for an updated analysis of the epidemiology of DR in China. The studies on the prevalence of DR were all community-based investigations, covering all the six geographic regions across China (see Figure 2). For those on risk factors for DR, more than half were community-based $(71 \%$, $\mathrm{n}=15$ ), whereas more than one third were conducted in East China (38\%, $\mathrm{n}=8$ ). There were no studies from Northwest China on which to base estimates of risk factors for DR (see Figure 2).

\section{Pooled prevalence of DR in China during 1990 and 2017}

By using random-effects meta-analysis, the pooled prevalence of any DR in general Chinese population was $1.14 \%(95 \% \mathrm{CI}=0.80-1.52)$, and that in people with DM was $18.45 \%$ (95\% CI $=14.77-22.43$ ) (Figure $3)$. According to the leave-one-out sensitivity analysis (Figure S3 in Online Supplementary Document), the pooled prevalence of any DR in general population varied from $1.08 \%(95 \% \mathrm{CI}=0.76-1.46)$ to $1.19 \%$ (95\% CI $=0.86-1.58)$, and that in people with DM ranged from $17.67 \%(95 \% \mathrm{CI}=14.12-21.53)$ to $19.01 \%(95 \% \mathrm{CI}=15.38-22.94)$, no single study significantly influenced the overall pooled prevalence in the meta-analysis. No publication bias was evident based on the visual evaluation of the funnel plot, Egger's test and Begg's test (Figure S4 in Online Supplementary Document).

For NPDR, the pooled prevalence in general population was $0.90 \%$ (95\% CI $=0.56-1.31)$, and that in peo-
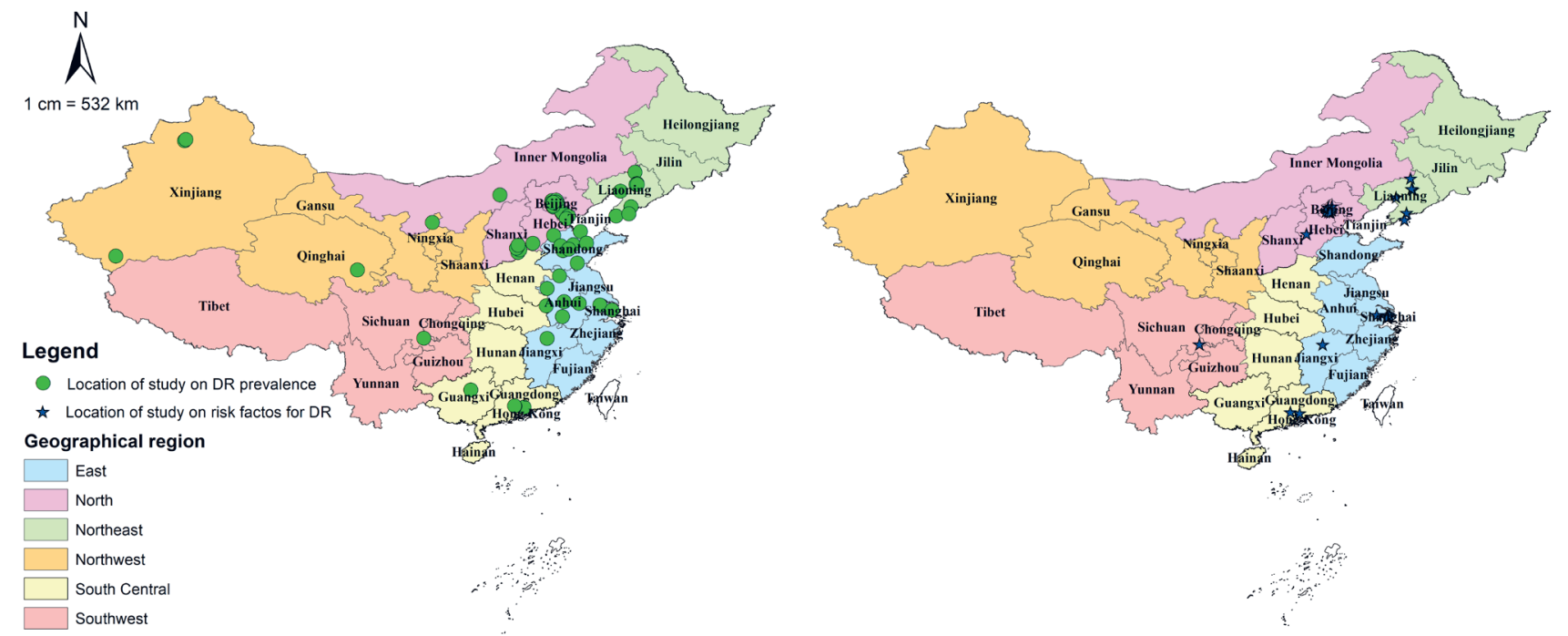

Figure 2. Geographical distribution of included studies on prevalence of and risk factors for diabetic retinopathy (DR) in China. 

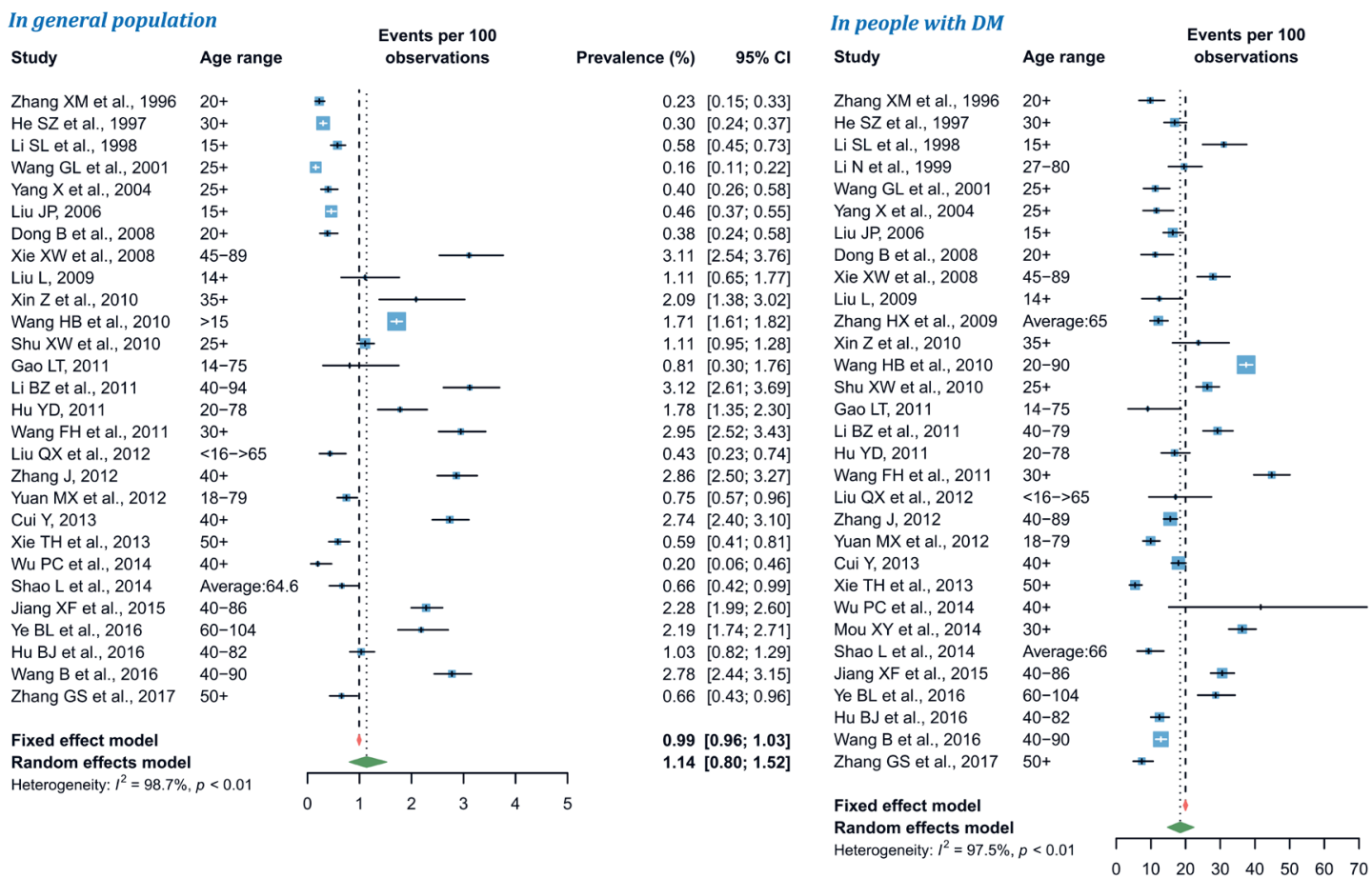

Prevalence (\%) $\quad 95 \% \mathrm{Cl}$

$9.82[6.57 ; 13.96]$ $16.85[13.78 ; 20.30]$ $31.02[24.92 ; 37.65]$ $19.57[15.05 ; 24.74]$ $11.26 \quad[7.88 ; 15.45]$ $11.61 \quad[7.72 ; 16.54]$ $16.31[13.55 ; 19.38]$ $11.22 \quad[7.17 ; 16.50]$ $27.90[23.34 ; 32.83]$ $12.41 \quad[7.40 ; 19.12]$ $12.15 \quad[9.72 ; 14.93]$ $23.68[16.22 ; 32.56]$ $37.46[35.61 ; 39.34]$ 26.27 [23.02; 29.73] $26.27[23.02 ; 29.73]$
$9.09 \quad[3.41 ; 18.74]$ 9.09
29.21 [25.03; 33.68] 16.81 [12.99; 21.23] 44.84 [39.68; 50.08] $17.11 \quad[9.43 ; 27.47]$ $15.57[13.70 ; 17.60]$ $9.93 \quad[7.68 ; 12.58]$ $17.94[15.90 ; 20.13]$ 41.67 [15.17; 72.33] $36.32[32.47 ; 40.30]$ $36.32[32.47 ; 40.30]$
$9.35 \quad[6.02 ; 13.70]$ $9.35[6.02 ; 13.70]$ 30.55 [27.22; 34.03] $28.67[23.50 ; 34.29]$ $12.46[9.96 ; 15.32]$ $12.88[11.37 ; 14.51]$ 7.39 [ $4.88 ; 10.64]$

19.99 [19.39; 20.60] 18.45 [14.77; 22.43]

Figure 3. Pooled prevalence of any diabetic retinopathy (DR) in general population and in people with DM by random-effects meta-analysis. There were 28 studies for synthesizing the prevalence of any DR in general population and 31 in people with DM.

ple with DM was 15.06\% (95\% CI=11.59-18.88) by use of random-effects meta-analysis (Figure 4). The leave-one-out sensitivity analysis suggested that no individual study significantly influenced the overall pooled prevalence in the meta-analysis (Figure S5 in Online Supplementary Document), where the pooled prevalence of NPDR in general population ranged from 0.79\% (95\% CI=0.49-1.14) to 0.99\% (95\% CI $=0.63-1.42)$ and that in people with DM from $13.92 \%(95 \% \mathrm{CI}=11.20-16.87)$ to $15.85 \%$ (95\% $\mathrm{CI}=12.48-19.53)$. Among studies that reported the prevalence of NPDR in general population, potential publication bias was revealed by the asymmetrical shape of funnel plot, Egger's test and Begg's test, whereas no publication bias was suggested for studies that reported the prevalence of NPDR in people with DM (Figure S6 in Online Supplementary Document).
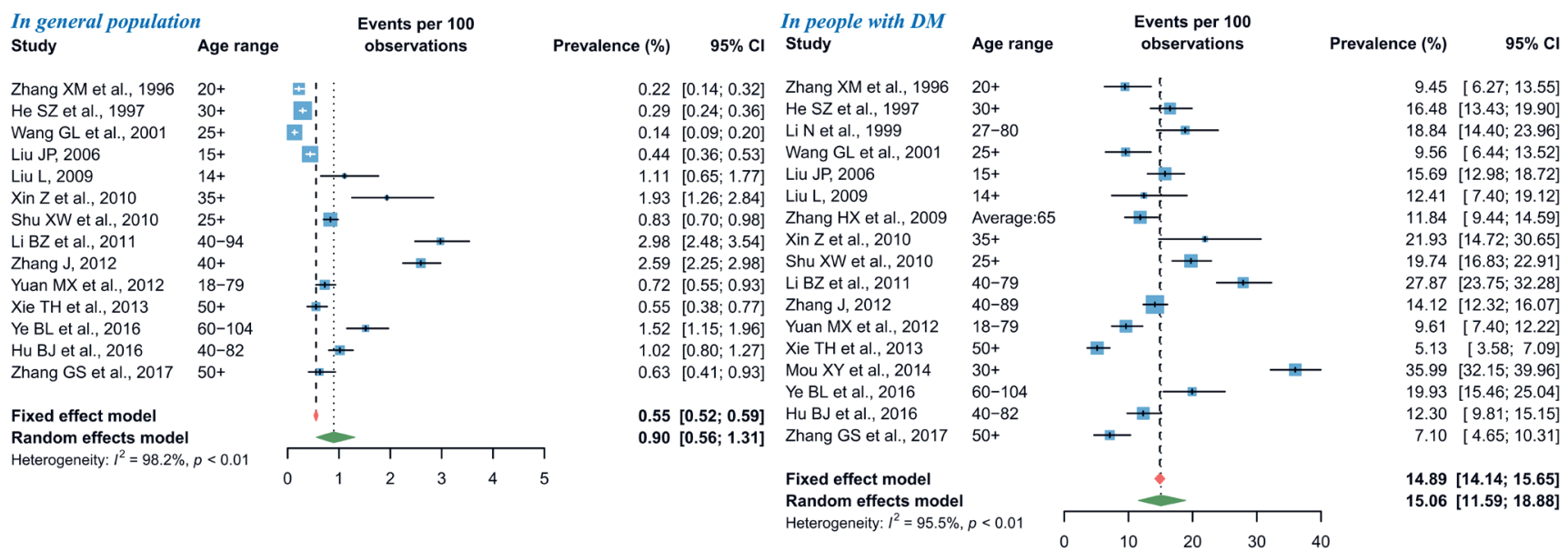

$14.89[14.14 ; 15.65]$

$15.06[11.59 ; 18.88]$

Figure 4. Pooled prevalence of nonproliferative diabetic retinopathy (NPDR) in general population and in people with diabetes mellitus (DM) by random-effects meta-analysis. There were 14 studies for synthesizing the prevalence of NPDR in general population and 17 in people with DM. 
As shown in Figure 5, the pooled prevalence of PDR from random-effects meta-analysis was 0.07\% (95\% $\mathrm{CI}=0.02-0.14)$ in general population and $0.99 \%(95 \% \mathrm{CI}=0.40-1.80)$ in people with $\mathrm{DM}$. The subsequent sensitivity analysis showed that the pooled prevalence of PDR was not affected unduly by a single study, where the pooled prevalence rates ranged from $0.05 \%(95 \% \mathrm{CI}=0.01-0.10)$ to $0.08 \%(95 \%$ $\mathrm{CI}=0.03-0.16)$ in general population, and from $0.76 \%(95 \% \mathrm{CI}=0.30-1.39)$ to $1.07 \%(95 \% \mathrm{CI}=0.43-$ 1.95) in people with DM (Figure S7 in Online Supplementary Document). For studies that reported the prevalence of PDR in general population, visual inspection of the funnel plot and Begg's test demonstrated some evidence of significant publication bias, which was not confirmed by the Egger's test. No publication bias was detected in the meta-analysis of PDR prevalence in people with DM (Figure S8 in Online Supplementary Document).
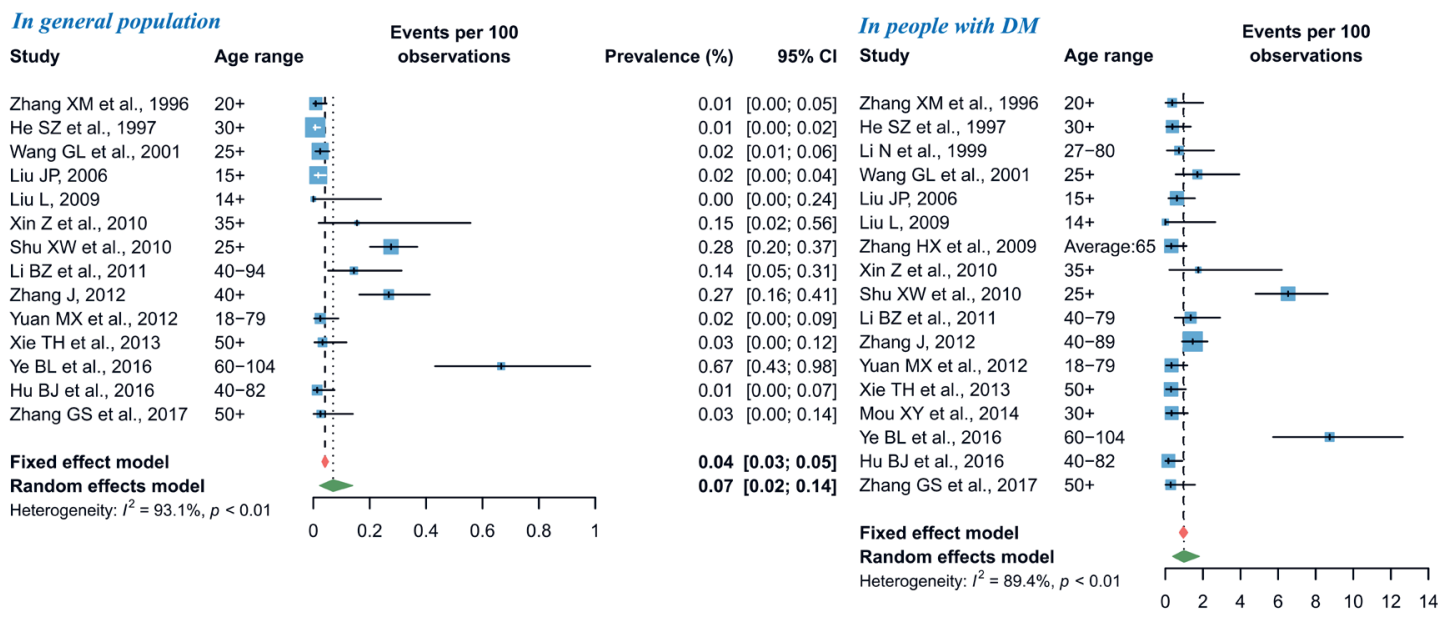

Prevalence $(\%) \quad 95 \% \mathrm{Cl}$

$0.36[0.01 ; 2.01]$ $0.37[0.05 ; 1.35]$ $0.72[0.09 ; 2.59]$ $1.71[0.56 ; 3.94]$ $0.62[0.17 ; 1.57]$ $0.00[0.00 ; 2.66]$ $0.00[0.00 ; 2.66]$ $0.31[0.04 ; 1.12]$ $1.75 \quad[0.21 ; 6.19]$ $6.53[4.80 ; 8.64]$ $1.35[0.50 ; 2.91]$ $1.46[0.89 ; 2.24]$ $0.33[0.04 ; 1.17]$ $0.30[0.04 ; 1.09]$ $0.33[0.04 ; 1.19]$ $8.74[5.74 ; 12.63]$ $0.16[0.00 ; 0.90]$ $0.28[0.01 ; 1.57]$

$0.96[0.75 ; 1.19]$ $0.99[0.40 ; 1.80]$

Figure 5. Pooled prevalence of proliferative diabetic retinopathy (PDR) in general population and in people with diabetes mellitus (DM) by random-effects meta-analysis. There were 14 studies for synthesizing the prevalence of PDR in general population and 17 in people with $\mathrm{DM}$.

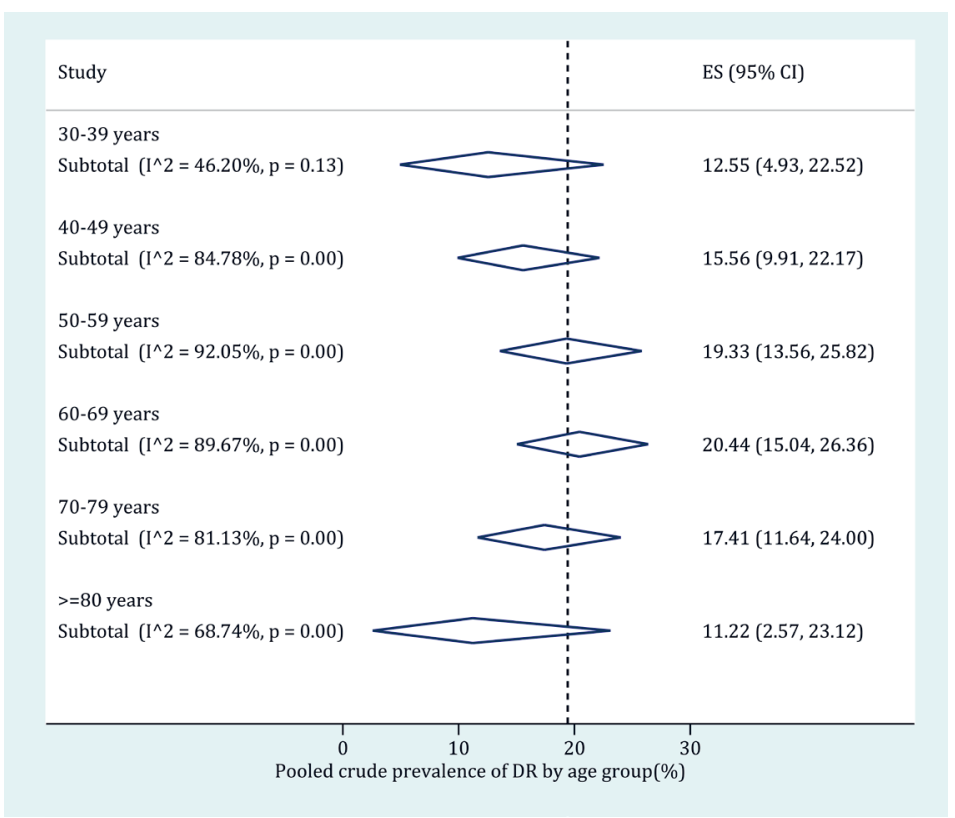

Figure 6. Age-specific prevalence of any diabetic retinopathy (DR) in people with diabetes mellitus (DM) by random-effects meta-analysis. The numbers of individual studies contributing to the synthesis of prevalence in each age group are 4 (for 30-39 years), 10 (for 40-49 years), 15 (for 50-59 years), 16 (for 60-69 years), 10 (for 70-79 years) and 9 (for 80-89 years) respectively.

\section{Subgroup meta-analysis and meta- regression of DR prevalence in people with DM}

The age-specific prevalence of any DR in people with DM was derived based on subgroup meta-analysis (Figure 6). The following age categories were adopted: $30-39$ years, $40-49$ years, 50-59 years, 60-69 years, 70-79 years and 80 years and older. Before the age of 70 years, the prevalence of any DR in people with DM kept rising from $12.55 \%$ (95\% CI $=4.93-22.52)$ in adults aged $30-39$ to $20.44 \%$ (95\% CI $=15.04-26.36)$ in those were 60 69 years old. Then the prevalence of any DR in people with DM started to decrease, until 11.22\% (95\% CI $=2.57-23.12)$ in elderly aged 80 years and above. The detailed process of synthesizing the prevalence of any DR in people with DM in each age category can be found in Figure S9 in Online Supplementary Document.

By pooling the prevalence of any DR in strata of DM duration group, it was revealed that the prevalence of any DR in people with DM substantially increased with the duration of DM. Four different DM duration groups were used: 0-year (newly de- 


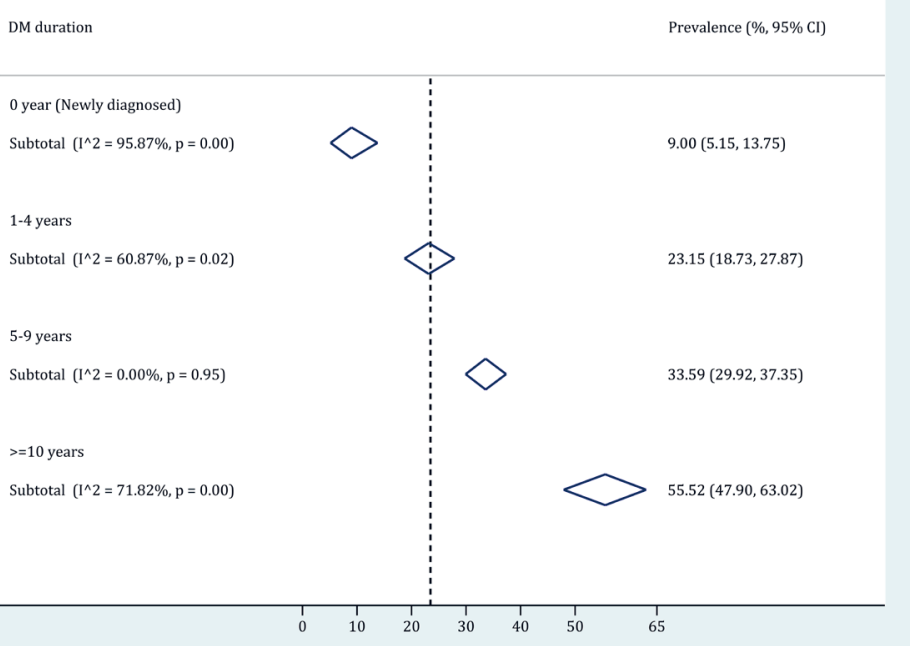

Figure 7. The prevalence of any diabetic retinopathy (DR) by diabetes mellitus (DM) duration group, using random-effects meta-analysis. The numbers of individual studies contributing to the synthesis of prevalence in each DM duration group are 13 (for newly diagnosed), 7 (for 1-4 years), 8 (for $5-9$ years) and 9 (for $\geq 10$ years) respectively.

Table 3. Odds ratios for any diabetic retinopathy in terms of setting, geographic region and study year from univariable meta-regression models, with $95 \%$ confidence intervals

\begin{tabular}{|c|c|c|c|c|}
\hline VARIABIE & $\begin{array}{l}\text { NuMBER OF } \\
\text { STUDIES }\end{array}$ & OR (95\% CI) & Z VALUE & P-value \\
\hline \multicolumn{5}{|l|}{ Gender:* } \\
\hline Female & \multirow{2}{*}{18} & Reference & Reference & Reference \\
\hline Male & & $0.98(0.88-1.08)$ & -0.47 & 0.639 \\
\hline \multicolumn{5}{|l|}{ Setting: } \\
\hline Urban & 12 & Reference & Reference & Reference \\
\hline Rural & 7 & $1.22(1.10-1.35)$ & 3.74 & $<0.001$ \\
\hline Mixed & 12 & $1.01(0.93-1.10)$ & 0.24 & 0.810 \\
\hline \multicolumn{5}{|l|}{ Geographic region: } \\
\hline North China & 11 & Reference & Reference & Reference \\
\hline Northeast China & 5 & $0.96(0.82-1.13)$ & -0.48 & 0.632 \\
\hline East China & 5 & $0.99(0.85-1.17)$ & -0.07 & 0.946 \\
\hline South Central China & 4 & $0.95(0.80-1.13)$ & -0.55 & 0.582 \\
\hline Southwest China & 1 & $0.94(0.69-1.28)$ & -0.39 & 0.699 \\
\hline Northwest China & 5 & $0.97(0.82-1.15)$ & -0.34 & 0.735 \\
\hline Study year (per decade) & 31 & $1.01(0.93-1.09)$ & 0.22 & 0.826 \\
\hline
\end{tabular}

tected), 1-4 years, 5-9 years and 10 years and longer. According to the subgroup meta-analysis (Figure 7), the DM duration-specific prevalence of any DR ranged from $9.00 \%(95 \% \mathrm{CI}=5.15-13.75)$ in people with newly detected DM to $55.52 \%$ (95\% $\mathrm{CI}=47.90-63.02)$ in those who had been diagnosed with DM for 10 years and longer. The process of synthesizing the prevalence of any DR in each DM duration group is detailed in Figure S10 in Online Supplementary Document.

According to the univariable meta-regression ( $\mathrm{Ta}$ ble 3), DM patients living in rural areas were more likely to have any DR than those in urban areas, with an OR of 1.22 (95\% CI=1.10-1.35). However, no evidence of gender difference, geographical variation or a secular trend in the prevalence of any DR in individuals with DM was observed.

\section{Synthesized effect size of risk factors for DR in people with DM}

A total of 21 studies described the risk factors for any DR in people with DM by multivariate logistic regression (Table S5 in Online Supplementary Document). Risk factors for any DR were reported in various ways, among which 11 were with consistent definitions and sufficient information, and therefore were included in evidence synthesis (Table 4). Advanced age was found to be negatively associated with any DR, which was partly in line with our estimates on the age-specific prevalence of any DR, where the prevalence of any DR started to decrease from 70 years onwards. In accordance with the estimated DM duration-specific prevalence of any DR in subgroup meta-analysis, longer DM duration was additionally recognised as a significant risk factor for any DR. DM patients receiving insulin treatment were almost two times more likely to have any DR than those who were not treated by insulin (OR 1.99 [95\% CI=1.34-2.95]). Moreover, elevated FBG level and higher HbAlc concentration were all identified as important risk factors for any DR, with ORs per unit increase of

Table 4. Synthesized effect size of 11 risk factors for any diabetic retinopathy in people with diabetes mellitus

\begin{tabular}{lcccc} 
Risk Factor & NUMBER OF STUDIES & OR (95\% Cl) & Z VALUE & P-VALUE \\
Risk factor 1-Advanced age (per year increase) & 4 & $0.96(0.93-1.00)$ & 2.26 & 0.024 \\
\hline Risk factor 2-Male & 5 & $1.41(0.88-2.27)$ & 1.42 & 0.156 \\
\hline Risk factor 3-DM duration (per year increase) & 12 & $1.09(1.06-1.12)$ & 5.93 & $<0.001$ \\
\hline Risk factor 4-Insulin treatment & 5 & $1.99(1.34-2.95)$ & 3.4 & 0.001 \\
\hline Risk factor 5-FBG (per mmol/L increase) & 9 & $1.33(1.12-1.59)$ & 3.23 & 0.001 \\
\hline Risk factor 6-2h PBG (per mmol/L increase) & 3 & $1.94(0.81-4.65)$ & 1.48 & 0.138 \\
\hline Risk factor 7-HbAlc (per \% increase) & 7 & $1.15(1.09-1.20)$ & 5.80 & $<0.001$ \\
\hline Risk factor 8-TC (per mmol/L increase) & 3 & $0.97(0.78-1.20)$ & 0.32 & 0.749 \\
\hline Risk factor 9-TG (per mmol/L increase) & 3 & $1.66(0.74-3.73)$ & 1.24 & 0.216 \\
\hline Risk factor 10-BMI (per kg/m increase) & 6 & $1.07(0.94-1.21)$ & 1.06 & 0.289 \\
\hline Risk factor 1l-SBP (per mmHg increase) & 5 & $1.03(1.00-1.07)$ & 1.96 & 0.05 \\
\hline OR
\end{tabular}

OR - odds ratio, CI - confidence interval, DM - diabetes mellitus, FBG - fasting blood glucose, PBG - postprandial blood glucose, HbAlc - glycated haemoglobin Alc, TC - total cholesterol, TG - triglyceride, BMI - body mass index, SBP - systolic blood pressure 
1.33 (95\% CI $=1.12-1.59)$ and 1.15 (95\% CI=1.09-1.20) respectively. Individual forest plots of meta-analyses for each risk factor can be found in Table S6 in Online Supplementary Document.

\section{National and subnational number of people with DR in 2010}

According to the CHARLS 2011, the weighted prevalence of DM was $17.22 \%(95 \% \mathrm{CI}=15.57-19.00)$ in middle-aged and older Chinese in 2010 (see Table S7 in Online Supplementary Document for more details). By applying the age-specific prevalence of any DR in people with DM and the corresponding age-specific DM cases, the number of middle-aged and older Chinese with any DR was estimated to be 13.16 million (95\% CI=8.95-18.00) in 2010, translating to an overall prevalence of 3.06\% (95\% CI=2.084.19) in general middle-aged and older Chinese and of $18.24 \%(95 \% \mathrm{CI}=12.41-24.95)$ in middle-aged and older Chinese with DM (Table 5). Based on the variations of population age structure, setting, mean FBG and mean HbAlc levels, the national DR cases were distributed into six geographic regions. As il-

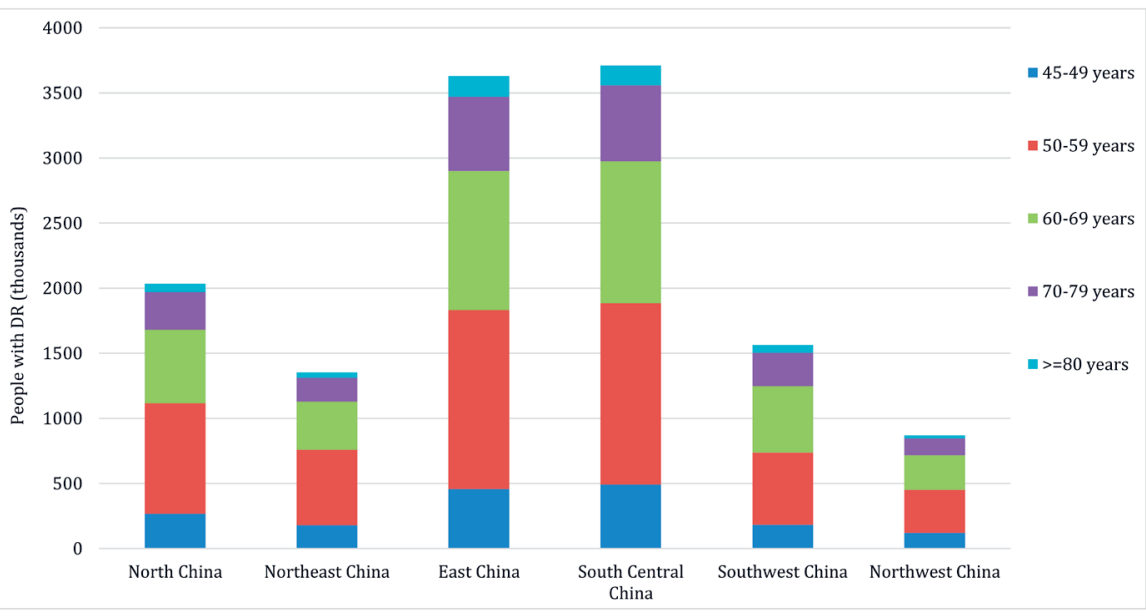

Figure 8. Estimated regional number of middle-aged and older Chinese with any diabetic retinopathy (DR) and contributing age groups in 2010. lustrated in Table 5 and Figure 8, South Central China harboured the most DR cases (3.71 million [95\% $\mathrm{CI}=2.52-5.09])$, while Northwest China had the least ( 0.87 million [95\% CI =0.60-1.18]). Regarding the prevalence of any DR at regional level, it was estimated that the prevalence of any DR in general middle-aged and older Chinese was the highest in North China (3.76\% [95\% CI=2.56-5.12]) and the lowest in Southwest China $2.55 \%$ [95\% CI=1.74-3.48]); For the prevalence of any DR in middle-aged and older Chinese with DM, it was the highest in Northwest China, while the lowest in East China (17.67\% [95\% CI $=11.97-24.24]$ ).

Table 5. Estimated prevalence and number of middle-aged and older Chinese with any diabetic retinopathy in China in 2010, by geographic region

\begin{tabular}{|c|c|c|c|}
\hline Regrow & $\begin{array}{l}\text { Previalence of any DR IN GeENeral } \\
\text { PEOPIE }(\%, 95 \% \text { CI) }\end{array}$ & $\begin{array}{c}\text { Prevalence of Any DR IN PEOPIE WITH } \\
\text { DM }(\%, 95 \% \text { CI) }\end{array}$ & $\begin{array}{l}\text { NUMBER OF PEOPLE WITH DR } \\
\text { (MILLON, 95\% CI) }\end{array}$ \\
\hline North China & $3.76(2.56-5.12)$ & $18.54(12.66-25.28)$ & $2.03(1.39-2.77)$ \\
\hline Northeast China & $3.22(2.20-4.39)$ & $18.93(12.94-25.81)$ & $1.35(0.92-1.84)$ \\
\hline East China & $2.74(1.86-3.76)$ & $17.67(11.97-24.24)$ & $3.63(2.46-4.98)$ \\
\hline South Central China & $3.31(2.25-4.54)$ & $17.97(12.19-24.63)$ & $3.71(2.52-5.09)$ \\
\hline Southwest China & $2.55(1.74-3.48)$ & $18.73(12.76-25.59)$ & $1.56(1.07-2.14)$ \\
\hline Northwest China & $3.09(2.12-4.20)$ & $19.39(13.30-26.35)$ & $0.87(0.60-1.18)$ \\
\hline China & $3.06(2.08-4.19)$ & $18.24(12.41-24.95)$ & $13.16(8.95-18.00)$ \\
\hline
\end{tabular}

DR - diabetic retinopathy, DM - diabetes mellitus, CI - confidence interval

\section{DISCUSSION}

By combining all available epidemiological data on the prevalence of DR in China from 1990 onwards, we estimated that in general population, the pooled prevalence of any DR, NPDR and PDR was $1.14 \%$ (95\% CI=0.80-1.52), 0.90\% (95\% CI=0.56-1.31) and 0.07\% (95\% CI=0.02-0.14); In people with DM, the pooled prevalence rates were $18.45 \%(95 \% \mathrm{CI}=14.77-22.43), 15.06 \%(95 \% \mathrm{CI}=11.59-18.88)$ and 0.99\% (95\% CI=0.40-1.80) for any DR, NPDR and PDR, respectively. The prevalence of any DR in DM patients peaked between 60 and 69 years of age, and increased steeply with the duration of DM. DM patients residing in rural China were at a higher risk to have any DR than those in urban areas. In addition, insulin treatment, elevated FBG level and higher HbAlc concentration were confirmed to be associated with a higher prevalence of any DR in people with DM. In 2010, a total of 13.16 million (95\% CI=8.95- 
18.00) Chinese aged 45 years and above were living with any DR, among whom the most were in South Central China and the least were in Northwest China. Collectively, these data suggest a considerable burden of DR in China.

To the best of our knowledge, this systematic review and meta-analysis provides a comprehensive estimation of the prevalence, risk factors and burden of DR in China. Although this study is subsequent to the first synthesized analysis by Liu and colleagues, many new merits are highlighted [22]. The principal strengths of this study include a comprehensive search strategy in both Chinese and English databases and a dual review process, which increased our ability to capture all studies on DR epidemiology in China. Ultimately, our estimation of DR prevalence was based on a total of 31 studies, which was more than 1.5 times the number of studies included in the first systematic review on DR in China. Another important feature that distinguished our study with the previous systematic review by Liu and colleagues was that only community-based studies incorporating both newly detected and already diagnosed DM cases were included for the estimation of DR prevalence, therefore the representativeness of our estimates can be greatly guaranteed. Regarding risk factors for DR, only studies that provided estimates of OR using multivariate study designs were included, therefore community-based, PHCM-based and registry-based studies could all contribute, ensuring a sufficient power for conducting reliable synthesized assessments. Furthermore, the definitions of risk factors in included studies were similar, as well as in the CHARLS 2011 [42,43]. Before pooling, an arcsine transformation was conducted to stabilise the variance of prevalence rates, which reduced the bias associated with small and large prevalence values on the pooled estimates to a large extent [32,33]. Although differences existed in the prevalence rates of DR across different subgroups, our detailed assessment of any DR prevalence by age and DM duration group, and identification of risk factors for any DR could serve as a source of primary information and guide policy making and rational planning of health services, especially in areas where local investigations on the epidemiology of DR are absent.

Before interpreting the findings, potential limitations of this systematic review and meta-analysis should be carefully considered. First, the pooled prevalence of NPDR and PDR in general population might have been affected by publication bias. Generally, publication bias arises because statistically significant results are more likely to be published than non-significant results, combining these studies for analysis could, therefore, introduce bias $[40,46,47]$. Unfortunately, we could not completely rule out publication bias because of the observational nature of our study. Second, there are inherent disadvantages in pooling prevalence form disparate studies. Due to the absence of stratified prevalence data for NPDR and PDR, we were not able to further explore sources of heterogeneity by subgroup meta-analysis and meta-regression for these two subtypes of DR. For any DR, sufficient data were available to pool the prevalence estimates and no publication was detected. However, our subgroup analysis on the prevalence of any DR by age group and DM duration group was only based on a limited number of studies that provided correspondingly stratified prevalence estimates. Third, only 11 risk factors with similar definitions across the included studies were systematically assessed, among which advanced age, longer DM duration, insulin treatment, elevated FBG level and higher HbAlc concentration were identified to be associated with a higher prevalence of any DR. However, because of the paucity of reported ORs, the effects of TC, TG and SBP should be further confirmed with new data coming in from future studies. In addition, previous studies have suggested that socioeconomic factors, including the availability and costs of DM management, were also likely to contribute to the disparities in DM severity and DR prevalence rates in different subgroups, but could not to be assessed in the current study [1,2,9]. Fourth, the number of DM cases in China for generating the national and subnational burden of any DR was derived from the CHARLS 2011, which was nationally representative but only conducted in middle-aged and older population [42,43]. Therefore, the estimated number of people with any DR in this study was only for people aged 45 years and above. When distributing the national DR cases into the six geographic regions, we only took the effects of four objective indicators into account, namely, advanced age, rural setting, elevated FBG level and higher HbAlc concentration. Other subjective risk factors (eg, insulin treatment and DM duration) and potential factors that might be associated with the prevalence of DR were not included in our analysis of regional burden of DR in China, which might reduce the reliability of our estimation at the subnational level. Bearing those limitations in mind, the results presented in this study should be interpreted judiciously.

In this study, significant heterogeneity was noted in pooling the prevalence rates of DR. The main sources of heterogeneity in the included studies pertained to the different characteristics of study population. After omitting each study at a time, the pooled prevalence of any DR was robust and consistent. The 
pooled prevalence of any DR in Chinese people with DM was lower in our study than that in the global DR study (18.45\% vs 25.08\%) [2]. Given that the estimated prevalence of any DR in Chinese people with DM presented in the global DR study was based on studies that were conducted both within and outside China, any differences in exposure levels of risk factors might explain this discrepancy. Compared with the pooled prevalence of any DR in Chinese people with DM reported by Liu and colleagues, our study revealed a relatively lower prevalence rate $(23.0 \%$ vs $18.45 \%)$ [22]. There are a number of possible reasons for this difference. First, the improvement of primary health care management in China might have resulted in a lower incidence of DR in recent years. Second, more recent investigations might include more newly detected DM patients. The incidence of DM is higher than that of DR, resulting in a relatively larger denominator for calculating the prevalence of DR. Most importantly, individual studies included in the systematic review and meta-analysis by Liu and colleagues were not solely focused on generally Chinese population, where both newly detected and diagnosed DM (self-reported physician diagnosed DM in some studies) cases should exist simultaneously. Two individual studies that were conducted in people with diagnosed DM were included in their final synthesis, the erroneous omission of people with newly detected or early-stage DM from the sample denominator would, therefore, lead to an overestimation of DR prevalence [22]. Furthermore, a study included in their synthesized analysis was specifically conducted in a group of people with higher risk for pre-diabetes (eg, people with familial DM history, hypertension, overweight/obesity, dyslipidemia, cardiovascular disease /stroke or a gestational history of large babies [for women]) rather than in general population, which will also add further possibility of an overestimation $[22,48]$.

In our analysis, the prevalence of any DR was found to peak between 60 and 69 years of age, which is in line with the age-specific prevalence estimates of DR among Americans $[4,49]$. In elderly with DM, the incidence of DR is relatively lower than that in younger people $[9,50]$. Given that DR is a marker for severe DM and other life-threatening complications, a reduced survival rate has been observed in older people living with DR [51-55]. Therefore, this pattern of declining DR prevalence in elderly seems to be driven by the combination of reduced incidence and improved mortality. Unsurprisingly, the prevalence of DR is strongly associated with the duration of DM, which has been validated by both sub-group meta-analysis and our meta-analysis on major risk factors for DR in this present study. This finding is consistent with other previous investigations and synthesized analyses $[2,55,56]$. As revealed by our analysis, more than half of all patients with DM for 10 years and longer will develop some degree of DR, underscoring the importance of optimal management of DM and early detection of DM complications in those living with DM. In this study, we noticed a higher prevalence of DR in DM patients living in rural China than that in those living in urban areas. This urban-rural disparity of DR prevalence in people with DM is in line with the study by Liu and colleagues [22]. In the Chinese context, awareness (a history of physician-diagnosed), treatment (proportion of individuals taking diabetes medications), and control (the proportion of individuals with an HbAlc concentration of less than 7.0\%) of DM among rural dwellers are all lower than that in urban dwellers, partly due to lower economic development level and restricted primary health resources in rural China $[23,51,57]$. The delayed diagnosis and non-optimal management of DM might be the primary causes of a higher prevalence of DR in rural China, but still need further confirmation in future studies.

Good glycemic control has long been recognized as one important factor for reducing vascular complications of DM, and it is also important in the prevention of DR $[16,58]$. In this study, higher levels of FBG and HbAlc have both been suggested as risk factors for DR in people with DM, which is in line with many previous investigations and synthesized results $[56,59]$. In addition, insulin treatment was identified to be with a higher odds of DR in DM patients according to our meta-analysis. Herein insulin treatment should not be simply concluded as a "bad treatment" which directly causes DR. In previous studies, it was suggested that a larger proportion of participants using insulin therapy were those with T1DM or with longer-duration of DM, and people with DR may have already been preferentially treated with insulin therapy $[56,60,61]$. In previous studies, higher SBP has been suggested as a risk factor for DR $[2,58]$. However, our meta-analysis of risk factors for DR only showed a slightly significant association between elevated SBP and DR. Given the effect of SBP on DR was only assessed based on five individual studies in our synthesized analysis, the lack of sufficient evidence logically calls for an updated analysis to better understand the role of SBP in the development of DR with new data coming in.

The increasing burden of DR might bring a higher pressure on available infrastructure and resources. Ideally, periodic eye examinations should be conducted by all patients with DM. Regular follow-up to detect significant retinopathy, together with prompt interventions when necessary, is believed to be the most ef- 
fective method to reduce potential DR-related visual disabilities $[1,3,62]$. In China, screening of DR has not been well established into the primary health care system, and the need for adequate DR eye care remains largely unaddressed [63,64]. Generally, DR screening could be evaluated in office or through telemedicine, and the latter has been suggested to be accurate and more cost-effective [65-67]. Furthermore, with the development of technology, a wholly automated approach with the assistance of artificial intelligence might be especially beneficial in under-developed areas. Even in established screening centres, those techniques also have a potential to substantially reduce the grading workload $[68,69]$.

With new epidemiological investigations emerging, the results of this study should be updated in a timely and regular manner. In addition, there remains a genuine need for prompting international standardized DR classification systems in Chinese scientific society, to facilitate communication and comparison across the world.

\section{CONCLUSIONS}

To conclude, this contemporary systematic review and meta-analysis estimated the prevalence, risk factors and burden of DR in China. The results from this study revealed a substantial burden of DR in China. Optimal screening of and interventions on DR should be implemented in the Chinese health system. Improved epidemiological studies on DR are still required to guide eye care programmes in China.

1 Cheung N, Mitchell P, Wong TY. Diabetic retinopathy. Lancet. 2010;376:124-36. Medline:20580421 doi:10.1016/S01406736(09)62124-3

2 Yau JW, Rogers SL, Kawasaki R, Lamoureux EL, Kowalski JW, Bek T, et al. Global prevalence and major risk factors of diabetic retinopathy. Diabetes Care. 2012;35:556-64. Medline:22301125 doi:10.2337/dc11-1909

3 Frank RN. Diabetic retinopathy. N Engl J Med. 2004;350:48-58. Medline:14702427 doi:10.1056/NEJMra021678

4 Kempen JH, O'colmain B, Leske MC, Haffner SM, Klein R, Moss SE, et al. The prevalence of diabetic retinopathy among adults in the United States. Arch Ophthalmol. 2004;122:552-63. Medline:15078674 doi:10.1001/archopht.122.4.552

5 Saaddine JB, Honeycutt AA, Narayan KV, Zhang X, Klein R, Boyle JP. Projection of diabetic retinopathy and other major eye diseases among people with diabetes mellitus: United States, 2005-2050. Arch Ophthalmol. 2008;126:1740-7. Medline:19064858 doi:10.1001/archopht.126.12.1740

6 Mazhar K, Varma R, Choudhury F, McKean-Cowdin R, Shtir CJ, Azen SP. Severity of diabetic retinopathy and health-related quality of life: the Los Angeles Latino Eye Study. Ophthalmology. 2011;118:649-55. Medline:21035872 doi:10.1016/j.ophtha.2010.08.003

7 Sharma S, Oliver-Fernandez A, Liu W, Buchholz P, Walt J. The impact of diabetic retinopathy on health-related quality of life. Curr Opin Ophthalmol. 2005;16:155-9. Medline:15870571 doi:10.1097/01.icu.0000161227.21797.3d

$8 \mathrm{Wu}$ L, Fernandez-Loaiza P, Sauma J, Hernandez-Bogantes E, Masis M. Classification of diabetic retinopathy and diabetic macular edema. World J Diabetes. 2013;4:290-4. Medline:24379919 doi:10.4239/wjd.v4.i6.290

9 Sivaprasad S, Gupta B, Crosby-Nwaobi R, Evans J. Prevalence of diabetic retinopathy in various ethnic groups: a worldwide perspective. Surv Ophthalmol. 2012;57:347-70. Medline:22542913 doi:10.1016/j.survophthal.2012.01.004

10 Group ETDRSR. Early photocoagulation for diabetic retinopathy: ETDRS report number 9. Ophthalmology. 1991;98:76685. Medline:2062512 doi:10.1016/S0161-6420(13)38011-7

11 Group DRSR. Photocoagulation treatment of proliferative diabetic retinopathy: clinical application of Diabetic Retinopathy Study (DRS) findings, DRS Report Number 8. Ophthalmology. 1981;88:583-600. Medline:7196564 doi:10.1016/ S0161-6420(81)34978-1 
12 Wilkinson CP, Ferris FL, Klein RE, Lee PP, Agardh CD, Davis M, et al. Proposed international clinical diabetic retinopathy and diabetic macular edema disease severity scales. Ophthalmology. 2003;110:1677-82. Medline:13129861 doi:10.1016/S0161-6420(03)00475-5

13 Leasher JL, Bourne RR, Flaxman SR, Jonas JB, Keeffe J, Naidoo K, et al. Global estimates on the number of people blind or visually impaired by diabetic retinopathy: a meta-analysis from 1990 to 2010. Diabetes Care. 2016;39:1643-9. Medline:27555623 doi:10.2337/dc15-2171

14 Pascolini D, Mariotti SP. Global estimates of visual impairment: 2010. Br J Ophthalmol. 2012;96:614-8. Medline:22133988 doi:10.1136/bjophthalmol-2011-300539

15 Klein BE. Overview of epidemiologic studies of diabetic retinopathy. Ophthalmic Epidemiol. 2007;14:179-83. Medline:17896294 doi:10.1080/09286580701396720

16 Mohamed Q, Gillies MC, Wong TY. Management of diabetic retinopathy: a systematic review. JAMA. 2007;298:902-16. Medline:17712074 doi:10.1001/jama.298.8.902

17 Zheng Y, He M, Congdon N. The worldwide epidemic of diabetic retinopathy. Indian J Ophthalmol. 2012;60:428. Medline:22944754 doi:10.4103/0301-4738.100542

18 Shaw JE, Sicree RA, Zimmet PZ. Global estimates of the prevalence of diabetes for 2010 and 2030. Diabetes Res Clin Pract. 2010;87:4-14. Medline:19896746 doi:10.1016/j.diabres.2009.10.007

19 Guariguata L, Whiting DR, Hambleton I, Beagley J, Linnenkamp U, Shaw JE. Global estimates of diabetes prevalence for 2013 and projections for 2035. Diabetes Res Clin Pract. 2014;103:137-49. Medline:24630390 doi:10.1016/j.diabres.2013.11.002

20 Williams R, Airey M, Baxter H, Forrester J, Kennedy-Martin T, Girach A. Epidemiology of diabetic retinopathy and macular oedema: a systematic review. Eye (Lond). 2004;18:963. Medline:15232600 doi:10.1038/sj.eye.6701476

21 Wong TY, Loon S, Saw S. The epidemiology of age related eye diseases in Asia. Br J Ophthalmol. 2006;90:506-11. Medline:16547337 doi:10.1136/bjo.2005.083733

22 Liu L, Wu X, Liu L, Geng J, Yuan Z, Shan Z, et al. Prevalence of diabetic retinopathy in mainland China: a meta-analysis. PLoS One. 2012;7:e45264. Medline:23028893 doi:10.1371/journal.pone.0045264

23 Xu Y, Wang L, He J, Bi Y, Li M, Wang T, et al. Prevalence and control of diabetes in Chinese adults. JAMA. 2013;310:94859. Medline:24002281 doi:10.1001/jama.2013.168118

24 Xia J, Wright J, Adams CE. Five large Chinese biomedical bibliographic databases: accessibility and coverage. Health Info Libr J. 2008;25:55-61. Medline:18251914 doi:10.1111/j.1471-1842.2007.00734.x

25 Fung IC. Chinese journals: a guide for epidemiologists. Emerg Themes Epidemiol. 2008;5:20. Medline:18826604 doi:10.1186/1742-7622-5-20

26 Moher D, Liberati A, Tetzlaff J, Altman DG. Preferred reporting items for systematic reviews and meta-analyses: the PRISMA statement. Ann Intern Med. 2009;151:264-9. Medline:19622511 doi:10.7326/0003-4819-151-4-200908180-00135

27 Stevens GA, Alkema L, Black RE, Boerma JT, Collins GS, Ezzati M, et al. Guidelines for accurate and transparent health estimates reporting: the GATHER statement. PLoS Med. 2016;13:e1002056. Medline:27351744 doi:10.1371/journal. pmed. 1002056

28 Klein R, Klein BE, Moss SE, Davis MD, DeMets DL. The Wisconsin Epidemiologic Study of Diabetic Retinopathy: III. Prevalence and risk of diabetic retinopathy when age at diagnosis is 30 or more years. Arch Ophthalmol. 1984;102:52732. Medline:6367725 doi:10.1001/archopht.1984.01040030405011

29 National Bureau of Statistics. Tabulation on the 2000 population census of the People's Republic of China. Beijing: China Statistics Press; 2002.

30 National Bureau of Statistics. Tabulation on the 2010 population census of the People's Republic of China. Beijing: China Statistics Press; 2012.

31 Freeman MF, Tukey JW. Transformations related to the angular and the square root. Ann Math Stat. 1950;21:607-11. doi:10.1214/aoms/1177729756

32 Barendregt JJ, Doi SA, Lee YY, Norman RE, Vos T. Meta-analysis of prevalence. J Epidemiol Community Health. 2013;67:974-8. Medline:23963506 doi:10.1136/jech-2013-203104

33 Nyaga VN, Arbyn M, Aerts M. Metaprop: a Stata command to perform meta-analysis of binomial data. Arch Public Health. 2014;72:39. Medline:25810908 doi:10.1186/2049-3258-72-39

34 Higgins JP, Thompson SG, Deeks JJ, Altman DG. Measuring inconsistency in meta-analyses. BMJ. 2003;327:557-60. Medline:12958120 doi:10.1136/bmj.327.7414.557

35 Higgins JP, Thompson SG. Quantifying heterogeneity in a meta-analysis. Stat Med. 2002;21:1539-58. Medline:12111919 doi:10.1002/sim.1186

36 Higgins JP, Green S. Cochrane handbook for systematic reviews of interventions. Vol 5. Oxford: Wiley Online Library; 2008.

37 Wallace BC, Schmid CH, Lau J, Trikalinos TA. Meta-Analyst: software for meta-analysis of binary, continuous and diagnostic data. BMC Med Res Methodol. 2009;9:80. Medline:19961608 doi:10.1186/1471-2288-9-80

38 Egger M, Smith GD, Schneider M, Minder C. Bias in meta-analysis detected by a simple, graphical test. BMJ. 1997;315:62934. Medline:9310563 doi:10.1136/bmj.315.7109.629

39 Begg CB, Mazumdar M. Operating characteristics of a rank correlation test for publication bias. Biometrics. 1994;50:1088101. Medline: 7786990 doi:10.2307/2533446

40 Peters JL, Sutton AJ, Jones DR, Abrams KR, Rushton L. Comparison of two methods to detect publication bias in meta-analysis. JAMA. 2006;295:676-80. Medline:16467236 doi:10.1001/jama.295.6.676 
41 United Nations, Department of Economic and Social Affairs, Population Division. World Population Prospects, the 2015 Revision. 2015. Available: https://esa.un.org/unpd/wpp/. Accessed: 8 January 2017.

42 Zhao Y, Strauss J, Yang G, Giles J, Hu P, Hu Y, et al. China health and retirement longitudinal study-2011-2012 national baseline users' guide. Beijing: National School of Development, Peking University. 2013:1-56.

43 Zhao Y, Hu Y, Smith JP, Strauss J, Yang G. Cohort profile: The China health and retirement longitudinal study (CHARLS). Int J Epidemiol. 2014;43:61-8. Medline:23243115 doi:10.1093/ije/dys203

44 Fowkes FGR, Rudan D, Rudan I, Aboyans V, Denenberg JO, McDermott MM, et al. Comparison of global estimates of prevalence and risk factors for peripheral artery disease in 2000 and 2010: a systematic review and analysis. Lancet. 2013;382:1329-40. Medline:23915883 doi:10.1016/S0140-6736(13)61249-0

45 Rudan I, Tomaskovic L, Boschi-Pinto C, Campbell H. Global estimate of the incidence of clinical pneumonia among children under five years of age. Bull World Health Organ. 2004;82:895-903. Medline:15654403

46 Sterne JA, Gavaghan D, Egger M. Publication and related bias in meta-analysis: power of statistical tests and prevalence in the literature. J Clin Epidemiol. 2000;53:1119-29. Medline:11106885 doi:10.1016/S0895-4356(00)00242-0

47 Stroup DF, Berlin JA, Morton SC, Olkin I, Williamson GD, Rennie D, et al. Meta-analysis of observational studies in epidemiology: a proposal for reporting. JAMA. 2000;283:2008-12. Medline:10789670 doi:10.1001/jama.283.15.2008

48 Pang C, Jia L, Jiang S, Liu W, Hou X, Zuo Y, et al. Determination of diabetic retinopathy prevalence and associated risk factors in Chinese diabetic and pre-diabetic subjects: Shanghai diabetic complications study. Diabetes Metab Res Rev. 2012;28:276-83. Medline:22139892 doi:10.1002/dmrr.1307

49 Cheng YJ, Imperatore G, Geiss LS, Wang J, Saydah SH, Cowie CC, et al. Secular changes in the age-specific prevalence of diabetes among US adults: 1988-2010. Diabetes Care. 2013;36:2690-6. Medline:23637354 doi:10.2337/dc12-2074

50 Varma R, Choudhury F, Klein R, Chung J, Torres M, Azen SP. Four-year incidence and progression of diabetic retinopathy and macular edema: the Los Angeles Latino Eye Study. Am J Ophthalmol. 2010;149:752-61.e1. Medline:20149342 doi:10.1016/j.ajo.2009.11.014

51 Bragg F, Holmes MV, Iona A, Guo Y, Du H, Chen Y, et al. Association between diabetes and cause-specific mortality in rural and urban areas of China. JAMA. 2017;317:280-9. Medline:28114552 doi:10.1001/jama.2016.19720

52 Targher G, Bertolini L, Zenari L, Lippi G, Pichiri I, Zoppini G, et al. Diabetic retinopathy is associated with an increased incidence of cardiovascular events in Type 2 diabetic patients. Diabet Med. 2008;25:45-50. Medline:18199131 doi:10.1111/j.1464-5491.2007.02327.x

53 van Hecke MV, Stehouwer CD, Polak BC, Fuller JH, Sjolie AK, Kofinis A, et al. Diabetic retinopathy is associated with mortality and cardiovascular disease incidence. Diabetes Care. 2005;28:1383-9. Medline:15920056 doi:10.2337/diacare.28.6.1383

54 Kramer CK, Rodrigues TC, Canani LH, Gross JL, Azevedo MJ. Diabetic retinopathy predicts all-cause mortality and cardiovascular events in both type 1 and 2 diabetes: meta-analysis of observational studies. Diabetes Care. 2011;34:123844. Medline:21525504 doi:10.2337/dc11-0079

55 Varma R, Torres M, Pe冈a F, Klein R, Azen SP. Prevalence of diabetic retinopathy in adult Latinos: the Los Angeles Latino eye study. Ophthalmology. 2004;111:1298-306. Medline:15234129 doi:10.1016/j.ophtha.2004.03.002

56 Zhang X, Saaddine JB, Chou C-F, Cotch MF, Cheng YJ, Geiss LS, et al. Prevalence of diabetic retinopathy in the United States, 2005-2008. JAMA. 2010;304:649-56. Medline:20699456 doi:10.1001/jama.2010.1111

$57 \mathrm{Xu} \mathrm{H}$, Luo J, Wu B. Self-reported diabetes education among Chinese middle-aged and older adults with diabetes. J Glob Health. 2016;6:020402. Medline:27698998 doi:10.7189/jogh.06.020402

58 Corcóstegui B, Durán S, González-Albarrán MO, Hernández C, Ruiz-Moreno JM, Salvador J, et al. Update on diagnosis and treatment of diabetic retinopathy: a consensus guideline of the working group of ocular health (Spanish Society of Diabetes and Spanish Vitreous and Retina Society). J Ophthalmol. 2017;2017:8234186. Medline:28695003 doi:10.1155/2017/8234186

59 Ding J, Wong TY. Current epidemiology of diabetic retinopathy and diabetic macular edema. Curr Diab Rep. 2012;12:34654. Medline:22585044 doi:10.1007/s11892-012-0283-6

60 Rema M, Premkumar S, Anitha B, Deepa R, Pradeepa R, Mohan V. Prevalence of diabetic retinopathy in urban India: the Chennai Urban Rural Epidemiology Study (CURES) eye study, I. Invest Ophthalmol Vis Sci. 2005;46:2328-33. Medline:15980218 doi:10.1167/iovs.05-0019

61 Zhao C, Wang W, Xu D, Li H, Li M, Wang F. Insulin and risk of diabetic retinopathy in patients with type 2 diabetes mellitus: data from a meta-analysis of seven cohort studies. Diagn Pathol. 2014;9:130. Medline:24972631 doi:10.1186/1746-1596-9-130

62 Ferris FL. How effective are treatments for diabetic retinopathy? JAMA. 1993;269:1290-1. Medline:8437309 doi:10.1001/ jama.1993.03500100088034

63 Vela C, Samson E, Zunzunegui MV, Haddad S, Aubin M-J, Freeman EE. Eye care utilization by older adults in low, middle, and high income countries. BMC Ophthalmol. 2012;12:5. Medline:22471351 doi:10.1186/1471-2415-12-5

64 Wang D, Ding X, He M, Yan L, Kuang J, Geng Q, et al. Use of eye care services among diabetic patients in urban and rural China. Ophthalmology. 2010;117:1755-62. Medline:20471689 doi:10.1016/j.ophtha.2010.01.019

65 Ting DSW, Cheung GCM, Wong TY. Diabetic retinopathy: global prevalence, major risk factors, screening practices and public health challenges: a review. Clin Experiment Ophthalmol. 2016;44:260-77. Medline:26716602 doi:10.1111/ ceo.12696

66 Jones S, Edwards R. Diabetic retinopathy screening: a systematic review of the economic evidence. Diabet Med. 2010;27:249-56. Medline:20536486 doi:10.1111/j.1464-5491.2009.02870.x 
67 Mansberger SL, Sheppler C, Barker G, Gardiner SK, Demirel S, Wooten K, et al. Long-term comparative effectiveness of telemedicine in providing diabetic retinopathy screening examinations: a randomized clinical trial. JAMA Ophthalmol. 2015;133:518-25. Medline:25741666 doi:10.1001/jamaophthalmol.2015.1

68 Usher D, Dumskyj M, Himaga M, Williamson TH, Nussey S, Boyce J. Automated detection of diabetic retinopathy in digital retinal images: a tool for diabetic retinopathy screening. Diabet Med. 2004;21:84-90. Medline:14706060 doi:10.1046/j.1464-5491.2003.01085.x

69 Wong TY, Bressler NM. Artificial intelligence with deep learning technology looks into diabetic retinopathy screening. JAMA. 2016;316:2366-7. Medline:27898977 doi:10.1001/jama.2016.17563 